\title{
Is There a Dissociative Subtype of Generalized Social Phobia?
}

\author{
Ali irfan Gül ${ }^{*}$, Gülnihal Gökçe Şimşek ${ }^{2}$, Sema İnanır ${ }^{3}$ and Özgül Karaaslan ${ }^{4}$ \\ ${ }^{1}$ Assisstant professor, Bozok Universirty, Medical Faculty, Department of Psychiatry \\ ${ }^{2}$ Yozgat Public Hospital, Turkey \\ ${ }^{3}$ Gaziosmanpaşa University, Turkey \\ ${ }^{4}$ Department of Psychiatry, Hospital of Government, Yozgat, Turkey
}

*Corresponding author: Ali irfan Gül, Assistant professor, Bozok Universirty, Medical Faculty, Department of Psychiatry, Tel: 905332184464 E-mail: gali3366@gmail.com

Received Date: June 05, 2014, Accepted Date: September 23, 2014, Published Date: September 30, 2014

Copyright: (c) 2014, Ali irfan Gül et al., This is an open-access article distributed under the terms of the Creative Commons Attribution License, which permits unrestricted use, distribution, and reproduction in any medium, provided the original author and source are credited.

\begin{abstract}
Objective: Dissociation in individuals with dissociative syndromes is primarily related to traumatic and/or shameful experiences. These situations may be re-experienced every time the individual is in a public arena and can lead to the manifestation of generalized social phobia (GSP). Therefore, the aim of this study was to investigate the severity of dissociative symptoms and the relationship of these symptoms to GSP.
\end{abstract}

Method: This study included 35 healthy volunteers and 51 patients with a diagnosis of GSP who visited the psychiatric outpatient clinic at the Y. Public Hospital or the B. University Medical Faculty Hospitals. All 51 patients with GSP completed the Liebowitz Social Anxiety Scale (LSAS), and the Dissociation Questionnaire (DIS-Q) was completed by the 51 patients as well as the 35 healthy volunteers.

Results: All participants completed the scales during their first session prior to the initiation of any treatment. The median LSAS anxiety score was $69.03 \pm 7.64$ and the mean avoidance score was $59.35 \pm 7.35$ in the GSP patient group. The mean DIS-Q score was $2.44 \pm 0.59$ in the GSP group and $1.67 \pm 0.38$ in the control group. GSP patients reported a significantly greater number of dissociative symptoms than did the control group $(Z=-6.00, P<0.001)$, and a moderately strong positive correlation was found between LSAS anxiety scores and DIS-Q scores (rho $=0.308$, $\mathrm{P}<0.05)$ in GSP patients.

Conclusion: Higher levels of dissociative symptoms were reported by GSP patients than by healthy controls. These findings indicate that dissociative symptoms may develop during the daily traumatic experiences to which individuals with GSP are exposed in social settings.

Keywords: Social phobia; Dissociation; Traumatic experience; Symptoms

\section{Introduction}

According to the Diagnostic and Statistical Manual of Mental Disorders, 4th Edition, Text Revision (DSM-IV-TR), a major characteristic of social phobia is the sustained experience of extreme fear in social situations, such as the fear of a shameful public performance. Occasionally, anxiety symptoms may emerge when an individual with social phobia is faced with performing in public, and this can develop into a panic attack [1]. A recent epidemiological study investigating social phobia found a lifetime prevalence of $4.9 \%$ in men and $9.5 \%$ in women [2]. Another epidemiological study conducted in France found a lifetime prevalence of $14.4 \%$ and reported that social phobia is the third most common mental disorder in that population [3]. It is thought that a combination of genetic and environmental factors contribute to the etiology of social phobia [4], which is categorized as either "limited" or "generalized" by the 10th revision of the International Classification of Diseases (ICD-10) and either "generalized" or "non-generalized" by the DSM-IV-TR.
Hypothetical thoughts or feelings experienced in a social situation can produce anxiety in a social phobic individual. According to this model, these anxiety symptoms are perceived by the individual as dangerous and salient, and an ongoing vicious cycle of symptoms and anxiety-coping strategies may occur [5]. Clinically anxious individuals can experience spontaneous visual images of themselves in social situations, and these images, somatic symptoms (e.g., palpitations), worries, anxious thoughts, negative emotions about themselves, and memories of actual social events may arise from interoceptive sources [6].

Dissociation is an interruption between the normal and subjective union of one or more psychological functions, perception, motor control, identity, memory, and awareness [7,8]. Many instances of acute dissociation are primarily related to traumatic and/or shameful experiences that the individual has endured [7]. Dissociative symptoms are also included in the diagnostic criteria for acute stress disorder, post-traumatic stress disorder, and somatization disorder [1], and a strong relationship exists between the stressors that usually result in dissociative symptoms and childhood trauma as well as physical, sexual, or emotional abuse [9-11].

Recently, there has been an interest in the possible relationship between social anxiety and dissociation $[12,13]$. This approach does 
Page 2 of 4

not conflict with accepted ideas regarding dissociation because dissociative disorders not only contribute to the development of psychological disorders but also influence interpersonal relationships [14]. A complicated relationship exists between social anxiety and dissociative symptoms, and we propose that dissociative symptoms are common in patients with generalized social phobia (GSP). Thus, this study aimed to investigate the incidence and severity of dissociative symptoms in patients with GSP and to examine how these symptoms affect the diagnosis and treatment of this disorder.

\section{Materials and Methods}

All procedures in this study were undertaken according to the Declaration of Helsinki. Approval was granted by the Institutional Review Board of the B. University Medical Faculty Noninvasive Clinical Studies Ethics Committee, and all participants provided informed consent.

\section{Sampling}

This study included 51 outpatients (35 female and 16 male) diagnosed with GSP who presented at the psychiatry clinic of Y. Public Hospital or B. University Hospital between March and July of 2013. The mean age of the patients was $29.66 \pm 7.19$ years (range: 18-49 years). The control group included 35 healthy subjects ( 19 women and 16 men) with a mean age of $31.88 \pm 7.09$ years (range: $21-55$ years). Those without GSP; those with a comorbid neurological, psychiatric, or medical condition or alcohol and/or drug use disorders; and those whose use of steroids resulted in psychiatric syndromes were excluded.

\section{Data Collection and Scales}

\section{Demographic information form}

The form used to collect demographic information was developed by the co-authors of the present study and included questions regarding the age, sex, educational status, and marital status of the participants.

\section{Liebowitz Social Anxiety Scale (LSAS)}

The Liebowitz Social Anxiety Scale (LSAS) was developed to assess the levels of avoidance and anxiety experienced by individuals with social phobia in interactive public situations and was designed to be administered by an interviewer with knowledge of this psychopathology. This scale is primarily used for individuals with social phobia but can easily be applied as a screening tool for groups that do not report clinical symptoms. The severity of anxiety and awareness are assessed in terms of each item, and the subscale scores are calculated as the sum of the total scores on both the anxiety and awareness sections. A cut-off point was not determined in the scale developed by Heimberg, Horner, Juster, Safren, Brown, Schneier, and Liebowitz [15], and a Turkish adaptation of the scale was developed by Soykan, Özgüven, and Gençöz [16].

\section{Dissociation questionnaire}

The DIS-Q was developed by Vanderlinden [17]. The Dissociation Questionnaire (DIS-Q) is a self-assessment test used to measure the severity of dissociative experiences and disorders in non-clinical and clinical samples with traumatic experiences. This scale consists of 63 items scored from 1 to 5 . The sum of these scores is divided by 63 , and a total average score is calculated. A Turkish study found that individuals with scores at least 2.5 points higher than the average score had a high probability of having a dissociative disorder. The DIS-Q was adapted into Turkish by Şar [18].

\section{Application}

The demographic and clinical data of the participants were recorded on an information form developed by the investigators. Patients with GSP were diagnosed by two psychiatrists using the Structured Clinical Interview for DSM-IV Axis I Disorders (SCID-I). Patients in this study completed the LSAS and the DIS-Q, whereas those in the control group completed only the DIS-Q.

\section{Statistical Analysis}

This work is an analytical study. All statistical analyses were conducted using SPSS version 17 (SPSS Inc.; Chicago, IL, USA), and descriptive statistics were analyzed in terms of medians and standard deviations. Scores on the LSAS and DIS-Q were compared between groups using the Mann-Whitney $U$ test and Spearman correlation analysis was employed to evaluate relationship between scores on these two tests. A p value $<0.05$ was considered to be statistically significant.

\section{Results}

The mean ages were $29.66 \pm 7.19$ years in the GSP group and 31.88 \pm 7.09 years in the control group ( $\mathrm{P}=0.12$ ). GSP patients had a mean of $10.94 \pm 2.88$ years of education, whereas those in the control group had a mean of $12.03 \pm 3.02$ years of education $(\mathrm{P}=0.09)$. The GSP group consisted of 23 married, 26 single, and two divorced participants, whereas the control group consisted of 21 married, 13 single, and one divorced subjects. Thus, there were not statistical differences between the GSP and the control group (Table 1).

\begin{tabular}{|l|l|l|l|}
\hline & S.Phobia & Control & $\mathbf{P}$ \\
\hline $\mathrm{N}$ & 51 & 35 & \\
\hline AGE (YEAR) (Mean \pm SD) & $\begin{array}{l}29.66 \quad \pm \\
7.19\end{array}$ & $31.88 \pm 7.09$ & 0.12 \\
\hline $\begin{array}{l}\text { EDUCATION (YEAR)(Mean } \pm \\
\text { SD) }\end{array}$ & $\begin{array}{l}10.94 \quad \pm \\
2.88\end{array}$ & $12.03 \pm 3.02$ & 0.09 \\
\hline GENDER & Male & 16 & 16 \\
\hline & Female & 35 & 19 \\
\hline MARITAL STATUS & Married & 23 & 21 \\
\hline & Single & 26 & 13 \\
\hline & Divorced & 2 & 1 \\
\hline
\end{tabular}

Table 1: Sociodemographic data of groups 
Page 3 of 4

\begin{tabular}{|c|c|c|c|c|}
\hline & & S.PHOBIA & CONTROL & Statistic \\
\hline \multirow[t]{5}{*}{$N$} & & 51 & 35 & \\
\hline & Anxiety $(\mathrm{M} \pm \mathrm{SD})$ & $69.03 \pm 7.64$ & & \\
\hline & Median & 69 & & \\
\hline & Avoidance $(\mathrm{M} \pm \mathrm{SD})$ & $59.35 \pm 7.35$ & & ${ }^{*} Z=-6.00$ \\
\hline & Median & 59 & & \\
\hline DIS_Q & $(\mathrm{M} \pm \mathrm{SD})$ & $2.44 \pm 0.59$ & $1.67 \pm 0.38$ & $p<0.001$ \\
\hline
\end{tabular}

Table 2: Descriptive statistics and statistical comparison of groups, ${ }^{\star} \mathrm{MWU}$

\begin{tabular}{|l|l|l|l|l|}
\hline & & Libovitz_Anxiety & Libovitz_Avoid. & Dis_Q \\
\hline Libovitz_Anxiety & rho & 1.000 & $0.828^{* *}$ & $0.308^{\star}$ \\
\hline & P & & 0.000 & 0.028 \\
\hline & N & 51 & 51 & 51 \\
\hline Libovitz_Avoidance & rho & $0.828^{* \star}$ & 1.000 & 0.273 \\
\hline & P & 0.000 & & 0.053 \\
\hline & N & 51 & 51 & 51 \\
\hline Dis_Q & rho & $0.308^{\star}$ & 0.273 & 1.000 \\
\hline & P & 0.028 & 0.053 & \\
\hline & N & 51 & 51 & 51 \\
\hline
\end{tabular}

Patients with anxiety are more sensitive to negative feedback than are healthy subjects partially because they have an automatic cognitive impulse to perceive this type of environmental stimulus as negative and/or threatening [20]. Similar findings regarding information processing were observed among women with both high and low levels of dissociative symptoms [21]. The relationship between the symptoms of dissociation and those of social phobia has been established more clearly than has any relationship between the etiologies of these disorders. For example, Simeon et al. [22] evaluated 117 patients with depersonalization disorder and found that $30 \%$ of patients met the diagnostic criteria for social phobia and $23 \%$ of patients met the diagnostic criteria for avoidant personality disorder. Furthermore, epidemiological investigations have demonstrated that $14.4 \%$ of patients with post-traumatic stress disorder experienced dissociative symptoms when in public situations [23] . Similar findings have been reported by other studies [24,25], and dissociation symptoms have also been found to more frequently occur in women

Table 3: Correlations of scales in patient group.

The GSP group had a mean anxiety score of $69.03 \pm 7.6$ and a mean awareness score of $59.35 \pm 7.35$ on the LSAS; they had a median score of $2.44 \pm 0.59$ on the DIS-Q. The control group had a median score of $1.67 \pm 0.38$ on the DIS-Q. The GSP patient group had a significantly higher score on the DIS-Q than did the control group $(\mathrm{Z}=-6, \mathrm{P}<0.001$; Table 2 and Figure 1). We found a very strong positive correlation between the LSAS anxiety and awareness scores $(\mathrm{rho}=0.828, \mathrm{P}<0.001)$, and the LSAS anxiety and DIS-Q scores were moderately positively correlated $(\mathrm{rho}=0.308, \mathrm{P}<0.05$; Table 3$)$.

\section{Discussion}

The primary finding of this study is the significantly higher levels of dissociative symptoms in the GSP than in the healthy control group $(\mathrm{Z}=-6, \mathrm{P}<0.001)$. Moreover, most GSP patients reported that they experienced dissociative symptoms most frequently in public areas, such as shopping centers and other crowded places, which indicates that these symptoms tend to be experienced by this population in stimulating social areas and situations. Derealization/ depersonalization (DR/DP) symptoms are more common under acute social stress, especially when an individual is faced with situations that are socially distressing [19]. Compared with healthy subjects, GSP patients experience relatively more DR/DP symptoms in social situations. Importantly, the post-event processing and anxious behaviors in which GSP patients continue to engage when in a safe setting prolong the social phobia dynamics and are related to DR/DP than in men $[25,26]$. Additionally, an experimental study found dissociation-like behaviors observed in male mice with Fragile-X syndrome in two types of anxiety-producing situations. In a Fragile- $X$ mouse model of generalized anxiety, experimental subjects exhibited reduced anxiety in a non-social elevated maze but social anxiety-like impaired performance in a test of social interaction [27].

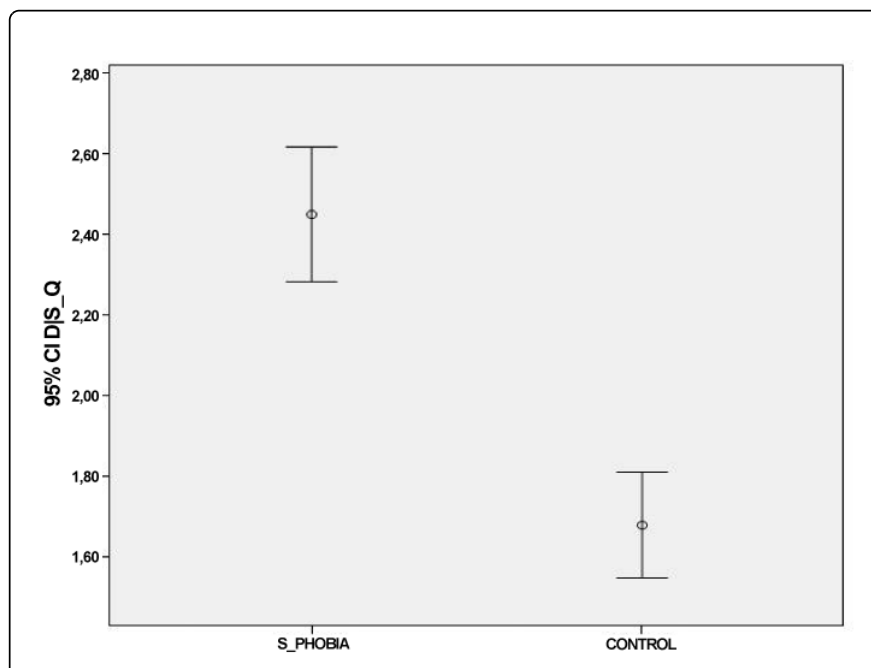

Figure 1: Comparison of social phobia and control groups. symptoms [19]. 
A history of trauma is observed less frequently in patients with obsessive-compulsive disorder than in those with social anxiety disorder, but patients with obsessive-compulsive disorder do not differ from those with social anxiety disorder in terms of the occurrence of dissociative symptoms [28]. However, the association between childhood trauma and subsequent dissociation in adulthood is supported by the incidence of social anxiety and other anxiety disorders among those who have experienced trauma [29]. A study of men with alcohol dependence found a significantly higher level of social anxiety in the dissociative patient subgroup than in subjects without dissociative symptoms [30]. Moreover, Hunter et al. [31] reported that the prevalence of DR/DP during panic attacks was 7.8-82.6\%; however, these findings are not generally accepted in the literature.

The present study found a positive and moderately strong correlation between LSAS anxiety scores and DIS-Q scores in patients with GSP. Although certain aspects of the present study involved only patients with GSP, the findings indicate that dissociative symptoms are quite frequent and severe in this psychiatric population. Dissociative symptoms in GSP patients typically occur in crowded areas, such as shopping centers and meetings. GSP patients are also more likely than normal population to be diagnosed with conditions such as vertigo or vestibular disorders and to avoid psychiatric treatment. Thus, a multidisciplinary approach may be useful for clarifying the nature of the psychiatric impairments in this group of patients.

\section{References}

1. Higa-McMillan CK, Smith RL, Chorpita BF, Hayashi K (2008) Common and unique factors associated with DSM-IV-TR internalizing disorders in children. J Abnorm Child Psychol 36: 1279-1288.

2. Wittchen HU, Stein MB, Kessler RC (1999) Social fears and social phobia in a community sample of adolescents and young adults: Prevalence, risk factors and co morbidity. Psychological Medicine 29: 309-323.

3. Lecrubier Y (1998) Comorbidity in social anxiety disorder: impact on disease burden and management. J Clin Psychiatry 59 Suppl 17: 33-38.

4. Rosenbaum JF, Biederman J, Pollock RA, Hirshfeld DR (1994) The etiology of social phobia. J Clin Psychiatry 55 Suppl: 10-16.

5. Clark DM, Wells A (1995) A cognitive model of social phobia. In Heimberg R G, Liebowitz M, Hope D A, Schneier F (Eds.), Social phobia: diagnosis, assessment and treatment. New York: Guilford.

6. Hackmann A, Clark DM, McManus F (2000) Recurrent images and early memories in social phobia. Behavior Research and Therapy 38: 601-610.

7. Spiegel D, Loewenstein RJ, Lewis-Fernandez R, Simeon D, Vermetten E, et al. (2011) Dissociative disorders in DSM-5, Depression And Anxiety 28: 17-45.

8. Tutkun H, Savas HA, Zoroglu SS, Esgi K, Herken H, et al. (2004) Relationship between alexithymia, dissociation and anxiety in psychiatric outpatients from Turkey. Isr J Psychiatry Relat Sci 41: 118-124.

9. Bob P, Selesova P, Raboch J, Kukla L (2013) 'Pseudoneurological' symptoms, dissociation and stress-related psychopathology in healthy young adults. BMC Psychiatry 13: 149.

10. Nijenhuis ERS (2001) Somatoform dissociation: Major symptoms of dissociative disorders. J Trauma Dissociation 1: 7-32.

11. Kihlstrom JF (2005) Dissociative disorders. Annu Rev Clin Psychol 1: 227-253.
12. Hinrichsen H, Wright F, Waller G, Meyer C (2003) Social anxiety and coping strategies in the eating disorders. Eat Behav 4: 117-126.

13. Michal M, Kaufhold J, Grabhorn R, Krakow K, Overbeck G, et al. (2005) Depersonalization and social anxiety. J Nerv Ment Dis 193: 629-632.

14. Liotti G (2006) A model of dissociation based on attachment theory and research. J Trauma Dissociation 7: 55-73.

15. Heimberg RG, Horner KJ, Juster HR, Safren SA, Brown EJ, et al. (1999) Psychometric properties of the Liebowitz Social Anxiety Scale. Psychol Med 29: 199-212.

16. Soykan, Ozgüven HD, Gençöz T (2003) Liebowitz Social Anxiety Scale: the Turkish version. Psychol Rep 93: 1059-1069.

17. Vanderlinden J, Van Dyck R, Vandereycken W, Vertommen H, Verkes R J (1993) The Dissociation Questionnaire (DIS-Q): Development and characteristics of a new self-reporting questionnaire. Clinical Psychology and Psychotherapyl: 21-27.

18. Sar V, K?z?ltan E, Kundakç? T, Bakim B, Yargic L I et al. (1998) the reliability and validity of the Turkish version of the Dissociation Questionnaire (DIS-Q). In 15th Fall Meeting of the International Society for the Study of Dissociation. Northbrook, Ill, ISSD.

19. Hoyer J, Braeuer D, Crawcour S, Klumbies E, Kirschbaum C (2013) Depersonalization/derealization during acute social stress in social phobia. J Anxiety Disord 27: 178-187.

20. Beck AT, Clark DA (1997) An information processing model of anxiety: automatic and strategic processes. Behav Res Ther 35: 49-58.

21. Waller G, Quinton S, Watson D (1995) Dissociation and the processing of threat-related information. Dissociation 8: 84-90.

22. Simeon D, Knutelska M, Nelson D, Guralnik O (2003) Feeling unreal: a depersonalization disorder update of 117 cases. J Clin Psychiatry 64: 990-997.

23. Stein DJ, Koenen KC, Friedman MJ, Hill E, McLaughlin KA, et al. (2013) Dissociation in posttraumatic stress disorder: evidence from the world mental health surveys. Biol Psychiatry 73: 302-312.

24. Waelde LC1, Silvern L, Fairbank JA (2005) A taxometric investigation of dissociation in Vietnam veterans. J Trauma Stress 18: 359-369.

25. Wolf EJ1, Lunney CA, Miller MW, Resick PA, Friedman MJ, et al. (2012) The dissociative subtype of PTSD: a replication and extension. Depress Anxiety 29: 679-688.

26. Steuwe C, Lanius RA, Frewen PA (2012) Evidence for a dissociative subtype of PTSD by latent profile and confirmatory factor analyses in a civilian sample. Depress Anxiety 29: 689-700.

27. Liu ZH, Smith CB (2009) Dissociation of social and nonsocial anxiety in a mouse model of fragile X syndrome. Neurosci Lett 454: 62-66.

28. Fontenelle LF, Domingues AM, Souza WF, Mendlowicz MV, de Menezes GB, et al. (2007) History of trauma and dissociative symptoms among patients with obsessive-compulsive disorder and social anxiety disorder. Psychiatr Q 78: 241-250.

29. Feerick MM, Snow KL (2005) the relationships between childhood sexual abuse, social anxiety and symptoms of posttraumatic stress disorder in women. Journal of Family Violence 20: 409-419.

30. Evren C, Sar V, Dalbudak E, Oncu F, Cakmak D (2009) Social anxiety and dissociation among male patients with alcohol dependency. Psychiatry Res 165: 273-280.

31. Hunter EC, Sierra M, David AS (2004) The epidemiology of depersonalisation and derealisation. A systematic review. Soc Psychiatry Psychiatr Epidemiol 39: 9-18. 